\title{
Artificial ${ }^{137} \mathrm{Cs}$ and natural ${ }^{40} \mathrm{~K}$ in mushrooms from the subalpine region of the Minya Konka summit and Yunnan Province in China
}

\author{
Jerzy Falandysz ${ }^{1}$ (D) Michał Saniewski ${ }^{2}$ - Ji Zhang ${ }^{3}$ - Tamara Zalewska ${ }^{2}$. \\ Hong-Gao Liu ${ }^{4}$ - Karolina Kluza ${ }^{1}$
}

Received: 4 July 2017 / Accepted: 9 October 2017 /Published online: 19 October 2017

(C) The Author(s) 2017

\begin{abstract}
A study on ${ }^{137} \mathrm{Cs}$ pollution and activity concentrations of ${ }^{40} \mathrm{~K}$ in mushrooms of the genera Cortinarius, Leccinum, Russula, Tricholoma, Tylopilus, and Xerocomus from two neighboring regions in southwest China in 20102013 revealed different patterns of pollution with ${ }^{137} \mathrm{Cs}$, which seemed to be highly dependent on climate conditions. Tricholoma matsutake was collected in Yunnan before and after the Fukushima Dai-ichi nuclear accident and showed similar contamination with ${ }^{137} \mathrm{Cs}$. Mushrooms from the elevation of 2800-3480 $\mathrm{m}$ above sea level on the east slope of Minya Konka and forest topsoil showed higher contamination with ${ }^{137} \mathrm{Cs}$ than mushrooms from the highlands of Yunnan. In detail, the activity concentration of ${ }^{137} \mathrm{Cs}$ in caps of mushrooms from Minya Konka were in the range $62 \pm 6-$ $280 \pm 150 \mathrm{~Bq} \mathrm{~kg}^{-1}$ dry biomass and from Yunnan at $<4.4$ $83 \pm 3 \mathrm{~Bq} \mathrm{~kg}^{-1}$ dry biomass. The climate in the region of the Minya Konka is much colder than in Yunnan, which seems to favor deposition of ${ }^{137} \mathrm{Cs}$ at higher altitudes from global atmospheric circulation. The activity concentration of ${ }^{40} \mathrm{~K}$ in mushrooms and soils highly exceeded that of ${ }^{137} \mathrm{Cs}$. The assessed annual effective doses for ${ }^{137} \mathrm{Cs}$ in $1 \mathrm{~kg}$ of consumed
\end{abstract}

Responsible editor: Georg Steinhauser

Jerzy Falandysz

jerzy.falandysz@ug.edu.pl

1 Laboratory of Environmental Chemistry \& Ecotoxicology, Gdańsk University, 63 Wita Stwosza Street, 80-308 Gdańsk, Poland

2 Institute of Meteorology and Water Management-Maritime Branch, National Research Institute, 42 Waszyngtona Av, Gdynia, Poland

3 Institute of Medicinal Plants, Yunnan Academy of Agricultural Sciences, Kunming, China

4 College of Agronomy and Biotechnology, Yunnan Agricultural University, Kunming, China mushrooms of the genera Leccinum and Xerocomus in Yunnan were low, i.e., in the range $<0.0043-$ $0.049 \pm 0.004 \mu \mathrm{Sv}$, while those for ${ }^{40} \mathrm{~K}$ were $0.26 \pm 0.02$ $0.81 \pm 0.09 \mu \mathrm{Sv}$.

Keywords Asia · Forest · Mushrooms · Topsoil · Radiocaesium $\cdot$ Potassium

\section{Introduction}

One of the most important anthropogenic radioactive contaminants in the environment is caesium $137\left({ }^{137} \mathrm{Cs}\right)$. It has a relatively long half-life of 30.05 years while the half-life of isotope ${ }^{134} \mathrm{Cs}$ is 2.07 years. ${ }^{137} \mathrm{Cs}$ contaminated the environment worldwide as a result of the nuclear weapon detonations and nuclear power plant accidents. The atmospheric nuclear weapon detonations were conducted largely in the northern hemisphere from 1945 until the end of the1970s, in West China up to 1980 and also in the South Pacific Ocean (Prăvălie 2014). Further, the nuclear power plant accident in Chernobyl in 1986 caused a serious radioactive contamination in Europe and beyond. A recent large-scale accident in the Fukushima Dai-ichi in 2011 also caused the release of significant amounts of radionuclides, mainly iodine and caesium isotopes (Steinhauser et al. 2014).

Food safety after Fukushima became the most pressing and most current issue with respect to radionuclide contaminations, since the results of food monitoring campaigns in Japan showed a specific contamination with ${ }^{137} \mathrm{Cs}$ of mushrooms and meat of game animals, such as wild boars (Sus scrofa), which eat mushrooms (Merz et al. 2015). Many mushrooms growing in the wild are known to be highly prone to contamination with artificial or natural radioactive compounds but also with heavy metals deposited or contained in 
the top layer of forest soils due to geochemical anomalies of parent soil material (Falandysz et al. 2017; Kirchner and Daillant 1998; Vaaramaa et al. 2009). Mushrooms from the wild are valued as organic food, and they still accumulate radionuclides and especially ${ }^{137} \mathrm{Cs}$ from the environment as a result of atmospheric nuclear weapon detonations and after major nuclear accidents (Betti et al. 2017; Chatterjee et al. 2017; Cocchi et al. 2017; Grodzinskaya et al. 2013; Letho et al. 2013; Saniewski et al. 2016; Steinhauser and Steinhauser 2016; Strumińska-Parulska et al. 2016).

Radioactive debris from nuclear detonations in the atmosphere at the high concentrations were observed in the stratosphere, and those from the accident in Chernobyl were spread largely near ground level and in a smaller portion also at the altitude of up to $15 \mathrm{~km}$ (Kownacka 2001). ${ }^{137} \mathrm{Cs}$ from the explosions in the atmosphere was spread throughout the atmosphere and deposited worldwide by means of both wet precipitation and dry deposition. It generally disappears from the stratosphere within a year after an event (Kownacka and Jaworowski 1994). Atmospheric removal of ${ }^{137} \mathrm{Cs}$ following the Chernobyl accident was high at locations with heavy rain and caused hot spot pollution of soils in some parts of Europe (Smith 1994; Strzelecki et al. 1993). Mountain ecosystems can be specifically prone to radioactive fallout after nuclear weapon detonations in the atmosphere and after major nuclear accidents (Salt 2007).

Little or nothing is known on radioactive fallout in the high montane regions of the World. We hypothesize that the subalpine area of Minya Konka (also called Mount Gongga or Gongga Shan) because of its Himalayan dimension, colder climate and geographical location, is more prone to contamination with ${ }^{137} \mathrm{Cs}$, and that forest soils and mushrooms there are more affected, when compared to neighboring areas at lower elevation, e.g., Yunnan Province, which borders to the Minya Konka region from the south. The Minya Konka region can receive some artificial radionuclides from nuclear detonations in the atmosphere and nuclear power plant accidents largely via the air mass currents at high altitudes from the global westerly circulation rather than from the East Asian and Indian monsoons. Those monsoons carry air masses and possible contaminants into the eastern regions of the Tibetan Plateau and Minya Konka in the Sichuan Province from the Pacific Ocean and regions of southern or southeastern Asia. To verify the hypothesis, both mushrooms and forest soil were sampled from the eastern slope in the subalpine area of Minya Konka and across Yunnan Province of China. They were examined for activity concentrations of ${ }^{137} \mathrm{Cs}$ and in parallel also for natural ${ }^{40} \mathrm{~K}$ using a gamma spectrometer with a high purity germanium detector. In addition, information on ${ }^{137} \mathrm{Cs}$ contamination and ${ }^{40} \mathrm{~K}$ accumulated in the flesh of some Cortinarius, Leccinum, Russula, Tricholoma, Tylopilus, and Xerocomus species from those two regions of different geography, topography, and climate conditions in southwest China, for which no previous information is available, were discussed.

\section{Materials and methods}

Two forest topsoil (dark soil) samples collected from the region of Minya Konka in 2012 and two red soils cores collected in Yunnan in 2016 and several species of mushrooms collected there were available for study (Fig. 1). Mushroom names in this study follow the nomenclature of Species Fungorum (Species Fungorum 2015). Mushrooms examined in this study include Cortinarius bovinus Fr. and C. collinitus Fr., Leccinum atrostipitatum Smith et Watling - current name Leccinum versipelle (Fr. \& Hök) Snell, L. chromapes (Forst.) Sing, L. extremiorientale (L.Vass.) Singer, L. griseum (Quél.) Sing, L. rugosiceps (Peck) Sing, L. scabrum (Bull.) Gray, L. variicolor Watling and L. versipelle (Fr. \& Hök) Snell, Russula grisea Fr. and R. puellaris Fr., Tricholoma pessundatum (S.Ito et Imai) Sing., Xerocomus spadiceus (Fr.) Quél-current name Boletus ferrugineus Schaeff. and X. versicolor E.-J. Gilbert-current name Hortiboletus rubellus (Krombh.) Simonini, Vizzini \& Gelardi (Table 2) (Species Fungorum 2015).

Each fruit body was separated into cap (with skin) and stipe in order to examine the distribution of ${ }^{137} \mathrm{Cs}$ and ${ }^{40} \mathrm{~K}$ between the morphological parts of the mushrooms (Table 2). The individual cap and stipe samples were sliced into pieces using a disposable plastic knife and pooled for each site $(n=7$ to 10 individuals per pool) - with composite samples representing each species, sampling location, and time of collection (Table 2). Subsequently, the mushroom samples were dried in plastic shelves of a commercial electric dryer (model: Ultra FD1000 dehydrator, Ezidri, Australia) at $65^{\circ} \mathrm{C}$ to constant mass. Dried fungal materials were pulverized in a porcelain mortar that was cleaned using a laboratory brush, deionized water, and detergent and further rinsed with distilled water and dried in an electrically heated laboratory dryer at $105^{\circ} \mathrm{C}$. The samples were kept in sealed polyethylene bags under dry conditions.

Topsoil (0-10 cm layer) samples from the Minya Konka region were dark soil and topsoil samples (layers of different length) from Yunnan were red earths. They were examined under the same conditions as mushrooms and data were presented on dry matter content (Table 1).

Activity concentrations of ${ }^{137} \mathrm{Cs}$ and ${ }^{40} \mathrm{~K}$ were determined using a gamma spectrometer with coaxial HPGe detector with a relative efficiency of $18 \%$ and a resolution of $1.9 \mathrm{keV}$ at $1.332 \mathrm{MeV}$ (with associated electronics) (Zalewska and Saniewski 2011). The equipment was calibrated using a multi-isotope standard, and the method was fully validated. The reference solution, "Standard solution of gamma emitting 
Fig. 1 Localization of the sampling sites (for details see Tables 1 and 2)

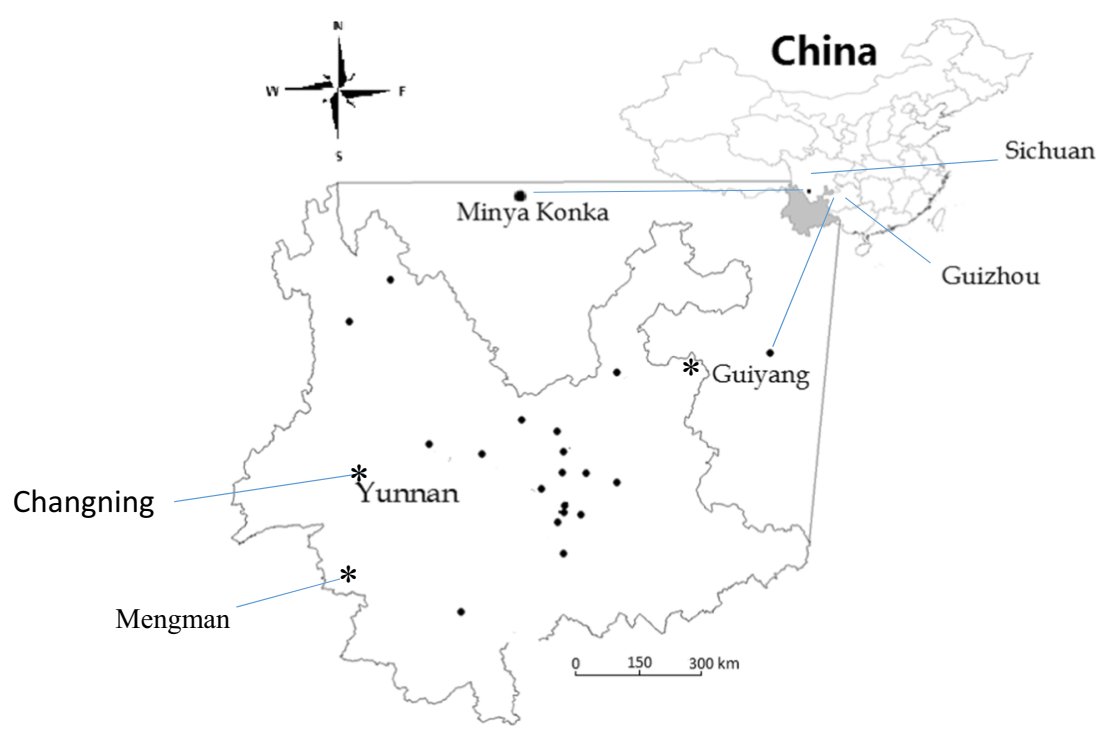

isotopes, code BW/Z-62/27/07" produced at IBJ-Świerk near Otwock in Poland, was used for preparing reference samples for equipment calibration. The same geometry of cylindrical dishes with $40 \mathrm{~mm}$ diameter (as applied for environmental samples) was used for reference samples during equipment calibration. Values of ${ }^{137} \mathrm{Cs}$ and ${ }^{40} \mathrm{~K}$ cap to stipe concentration quotients (index $\mathrm{Q}_{\mathrm{c} / \mathrm{s}}$ ) were also calculated.

The laboratory involved was subjected to routine checks to ensure high standards of analytical quality and analytical control and participated successfully in the inter-comparison exercises organized by IAEA-MEL Monaco (IAEA-414, Irish and North Sea Fish) to confirm the reliability and accuracy of the method (Zalewska and Saniewski 2011). Repeated analysis gave values of ${ }^{137} \mathrm{Cs}, 5.06 \pm 0.64 \mathrm{~Bq} \mathrm{~kg}^{-1}$ d.b. and ${ }^{40} \mathrm{~K}$, $474.5 \pm 19.3 \mathrm{~Bq} \mathrm{~kg}^{-1}$ d.b., while the estimated target values were equal to $5.18 \pm 0.10 \mathrm{~Bq} \mathrm{~kg}^{-1}$ d.b. for ${ }^{137} \mathrm{Cs}$ and $481 \pm 16 \mathrm{~Bq} \mathrm{~kg}^{-1}$ d.b. for ${ }^{40} \mathrm{~K}$. In the gamma spectrometry measurements, the limit of quantification was calculated using GENIE 2000 as a Minimum Detectable Activity (MDA) as defined by Curie (1968). All numerical data gained were recalculated for dehydrated fungal material $\left(\right.$ at $105^{\circ} \mathrm{C}$ ) and all data were decay corrected back to the time of sampling.

\section{Results and discussion}

${ }^{137} \mathrm{Cs}$ and ${ }^{40} \mathrm{~K}$ activity concentrations in topsoil Activity concentrations of ${ }^{137} \mathrm{Cs}$ in topsoil (dark soil, $0-10 \mathrm{~cm}$ layer) collected from the stands of Cortinarius collinitus in Minya Konka was in the range $41 \pm 1-79 \pm 2$ and was an order of magnitude less for topsoil layers $(0-5$ and $0-10 \mathrm{~cm})$ from two sites in Yunnan (Table 1). The upper layer $(0-10 \mathrm{~cm})$ of soils from the locations in Yunnan was evidently less polluted with ${ }^{137}$ Cs compared to Minya Konka.

Results on a weaker contamination with ${ }^{137} \mathrm{Cs}$ in topsoil in this study correspond well with a few data available for soils from a region situated around $1000 \mathrm{~km}$ west of the locations in Yunnan. Namely, soils (sample size $n=26$ ) from the eastern
Table 1 Activity concentrations of ${ }^{137} \mathrm{Cs}$ and ${ }^{40} \mathrm{~K}\left(\mathrm{~Bq} \mathrm{~kg}{ }^{-1}\right.$ dry matter \pm a counting uncertainty) in forest topsoil

\begin{tabular}{|c|c|c|c|c|c|}
\hline \multirow[t]{2}{*}{ Site } & \multirow[t]{2}{*}{ Month and year } & \multirow{2}{*}{$\begin{array}{l}\text { Elevation } \\
\text { (m a.s.1.) }\end{array}$} & \multirow{2}{*}{$\begin{array}{l}\text { Topsoil layer } \\
(\mathrm{cm})\end{array}$} & \multicolumn{2}{|c|}{$\mathrm{Bq} \mathrm{kg}^{-1}$ d.m. } \\
\hline & & & & ${ }^{137} \mathrm{Cs}$ & ${ }^{40} \mathrm{~K}$ \\
\hline Minya Konka & July, 2012 & 3000 & $0-10$ & $79 \pm 2$ & $280 \pm 16$ \\
\hline Minya Konka & July, 2012 & 3000 & $0-10$ & $41 \pm 1$ & $500 \pm 20$ \\
\hline \multirow[t]{3}{*}{ Yunnan, Changning } & October, 2016 & 1950 & $0-1$ & $2.8 \pm 0.8$ & $270 \pm 24$ \\
\hline & & & $1-5$ & $7.5 \pm 0.7$ & $340 \pm 19$ \\
\hline & & & $5-10$ & $0.5 \pm 0.4$ & $320 \pm 16$ \\
\hline \multirow[t]{4}{*}{ Yunnan, Mengman } & October, 2016 & 908 & $0-1$ & $0.7 \pm 0.5$ & $160 \pm 16$ \\
\hline & & & $1-5$ & $4.9 \pm 0.6$ & $170 \pm 16$ \\
\hline & & & $5-10$ & $3.3 \pm 0.3$ & $150 \pm 14$ \\
\hline & & & $10-25$ & $<0.5$ & $160 \pm 12$ \\
\hline
\end{tabular}

a.s.l. above sea level 
part of Kumaun Himalaya (west of Nepal) in India at an elevation of around $2000 \mathrm{~m}$ a.s.l. showed activity concentrations of ${ }^{137} \mathrm{Cs}$ at $2.8 \pm 2.2$ (range 0.4-8.2) $\mathrm{Bq} \mathrm{kg}^{-1}$ (Ramola et al. 2011), which were at the same order of magnitude as those in Yunnan (Table 1). Weather condition (primarily wet deposition) has a great effect on removing of airborne pollutants from the atmosphere. ${ }^{137} \mathrm{Cs}$ from aboveground nuclear detonations and global circulation in the stratosphere can re-enter the lower atmosphere and further precipitate on the earth's surface by wet precipitation (Longmore 1982), and this was noted for fallout from the Chernobyl accident (Smith 1994; Strzelecki et al. 1993). A "hot spot" type contamination as has been evidenced for a forested land affected by ${ }^{137} \mathrm{Cs}$ deposited from the Chernobyl accident release can also be an example (Mietelski et al. 2010). In a study by DeWayne et al. (1999), ${ }^{137} \mathrm{Cs}$ become trapped at greater than background activity concentrations in glacier ice during the 1940s-1960s and also in 1998 in the Nangpai Gosum Glacier, which is located $25 \mathrm{~km}$ west northwest of Mount Everest in the Himalayas of Nepal.

The magnitude and difference in forest topsoil contamination with ${ }^{137} \mathrm{Cs}$ between the Minya Konka and Yunnan sites seem to be related largely to substantial differences in climatic conditions because of different elevation and geographical location. The subalpine region in Minya Konka, because of its cold conditions, is more sensitive to contamination by airborne persistent compounds transported at higher altitudes in a global atmospheric circulation pattern where they can be trapped by cold temperature and wet precipitation (Falandysz et al. 2014).

Is well documented, that the Minya Konka region has a mean annual temperature of $4.2^{\circ} \mathrm{C}$, with a minimum mean value in January of $-4.6^{\circ} \mathrm{C}$ and a maximum mean value in July of $12.5^{\circ} \mathrm{C}$, while the mean annual precipitation was $1947.4 \mathrm{~mm}$ in 1988-2010 (Wu et al. 2013). On a contrary, Yunnan Province primarily has a subtropical monsoon climate and is more influenced from the Pacific and Indian oceans and it has temperate summers and mild to warm winters, except for the subtropical region of Xishuangbanna in the south, where it is warm, and also the plateau region of Shangri-La in the northwest, where temperatures are moderate.

The Province of Yunnan has a mean annual temperature of $16.3^{\circ} \mathrm{C}$, with minimum mean values in ranges from 8 to $17^{\circ} \mathrm{C}$ in January and 21 to $27^{\circ} \mathrm{C}$ in July, while the mean annual precipitation is $1105.12 \mathrm{~mm}$ in most regions and more than $1600 \mathrm{~mm}$ in the south (Luo et al. 2016). According to Quin et al. (2015), no distinct change in annual precipitation rate was noted in southwestern China including Yunnan-Guizhou Plateau during 1961-2000 while there were significant changes for monthly precipitation overall, with increasing trends for maximum precipitation, rainy day intensity, and annual precipitation in the first half of the year in 1961-2000. Some recent modeling revealed that in Yunnan "the annual average temperature had been increasing, the annual precipitation was decreasing in the east, northeast, south and west of the province, and particularly, there was an obvious decreasing trend of precipitation in the rainy (May-October) season" (Ren et al. 2017).

Data on the environmental impact of the aboveground nuclear detonations and following the Chernobyl accident were sparse from China, but the impact of the Chernobyl accident was considered negligible, e.g., in the region of the city of Xi'an in the central region of China (Pang et al. 1989). Japan's Fukushima Dai-ichi nuclear accident was considered as having little or no impact on the environmental radiation levels in the region of the Xi' an in Shaanxi Province in the central part of China, and without impact on the environment and food chain from the farmlands of Sichuan Province in western China (Liu et al. 2013; Shuai et al. 2016). Fukushima's radioactive plume arrived via global atmospheric circulation also to the southeastern fringe of the Tibetan plateau in the region of Minya Konka and to the northern part of the Yungui plateau; this was detected in the Guiyang region in Guizhou province in March 24-31, 2011. The Guiyang region also received a radioactive plume in the second, the regional scale event, on April 7-14, 2011, when air masses moved at lower altitudes from eastern Asia (Wan et al. 2014). Nevertheless, no data on the surface contamination with ${ }^{134}$ ${ }^{137} \mathrm{Cs}\left(\mathrm{Bq}\right.$ per $\mathrm{m}^{2}$ ) are available for Minya Konka, Yunnan, or elsewhere in southwest China.

As found in this study, the degree of pollution with ${ }^{137} \mathrm{Cs}$ of the upper layer of red soil (topsoil) in the Changning and Mengman sites in southwestern Yunnan was largely similar $\left(<10 \mathrm{~Bq} \mathrm{~kg}^{-1}\right.$ dry matter (d.m.)), while some differences were observed for the interim soil layers. The uppermost organic $(0-1 \mathrm{~cm})$ layer in the Changning and Mengman sites showed on a smaller activity concentration of ${ }^{137} \mathrm{Cs}$ than the interim layers of $2-5 \mathrm{~cm}$ (Changning) and of $2-5$ to $6-10 \mathrm{~cm}$ (Mengman), where ${ }^{137} \mathrm{Cs}$ activity concentrations were greater but further decreased with depth (Table 1). In the case of ${ }^{40} \mathrm{~K}$, forest topsoil in the Changning site was twice as high in this nuclide than topsoil from the Mengman site, while activity concentrations of ${ }^{40} \mathrm{~K}$ were in practice almost constant between the layers.

It is known that airborne ${ }^{137} \mathrm{Cs}$ when deposited on forest soil becomes initially trapped in the uppermost "organic" layer $(\sim 0-10 \mathrm{~cm}$ layer) and further, but very slowly migrates down in a soil profile (Fesenko et al. 2001; Letho et al. 2013; Mietelski et al. 2010; Yoshida and Muramatsu 1994). Downward trends of ${ }^{137} \mathrm{Cs}$ differ, depending on many conditions such as the soil itself, topography, vegetation, fungi, etc. (Letho et al. 2013). Nevertheless, a downward trend of ${ }^{137} \mathrm{Cs}$ migration in red soils of southwestern Yunnan (Table 1) can be considered to some degree as similar to the rate of a downward migration as observed for this nuclide in forest soil elsewhere, but this was not studied in detail in this work. 
A small fraction of deposited ${ }^{137} \mathrm{Cs}$ can, because of a pores in the forest soil, migrate down a soil profile quickly and not be adsorbed by a layer rich in humus (organic) (Teramage et al. 2014). This can have consequences for efficiency of ${ }^{137} \mathrm{Cs}$ pick-up (also radioactive ${ }^{134} \mathrm{Cs}$ ) from soil substrata by mycelium and its bio-concentration in fruit bodies by certain mushrooms. All isotopes of Cs use the same pathway for uptake that exists for natural and non-radioactive isotopes of Cs $\left({ }^{133} \mathrm{Cs}\right)$ (Tsukada et al. 1998). Mushrooms, both saprobic and mycorrhizal, take up mineral constituents from the substrate where the mycelium lives - typically from litter, soil, soil solution, and decaying organic matter (Falandysz and Treu 2017).

\section{${ }^{137} \mathrm{Cs}$ and ${ }^{40} \mathrm{~K}$ activity concentrations in mushrooms} Yunnan Province in China is the major supplier of wild growing mushrooms both for the domestic market and for export. Due to a high biodiversity and an abundance of species, there is also a great tradition for foraging and eating mushroomsranging from the subtropical region of Xishuangbanna up to the Tibetan region of Shangri-La and the Pudacuo National Park in Diqing in the northwest of Yunnan (Falandysz et al. $2016 \mathrm{~b}$ and 2017). The subalpine region on the east slope of the Gongga Shan Mountain in the area of the Hailuogou National Park is also diverse in species of mushrooms, while the forest (jungle) there is barely accessible because of dangerous slopes, rocks, dense vegetation, and other mountain hazards. Hence, edible mushrooms from the Hailuogou National Park are collected only by some locals there and in rather small quantity.

It was expected that the deposition of airborne ${ }^{137} \mathrm{Cs}$ in the subalpine area of Minya Konka from global fallout, and with absence of local and regional sources of emission, should be better reflected in mushrooms and topsoil from there, compared to mushrooms and topsoil from the neighboring northern, central, and southern regions of Yunnan Province. Available data on radioactivity levels in mushrooms from some main producing countries such as China are considered as insufficient (Falandysz et al. 2015a, b, 2016a and 2017).

Activity concentrations of ${ }^{137} \mathrm{Cs}$ in mushrooms collected across of Yunnan ranged from $4.9 \pm 1.3$ to $83 \pm 3 \mathrm{~Bq} \mathrm{~kg}^{-1}$ d.b. in the caps and from $3.9 \pm 1.3$ to $37 \pm 3 \mathrm{~Bq} \mathrm{~kg}^{-1}$ d.b. in the stipes (Fig. 2). Only in the case of a few samples, the ${ }^{137} \mathrm{Cs}$ activity concentrations were below the limit of detection: in four samples of the caps $\left(<4.4 \mathrm{~Bq} \mathrm{~kg}^{-1}\right.$ d.b.) and three samples of stipes $\left(<3.8 \mathrm{~Bq} \mathrm{~kg}^{-1}\right.$ d.b. $)$. Activity concentrations of ${ }^{137} \mathrm{Cs}$ in mushrooms collected from the subalpine area of Minya Konka were clearly higher and ranged from $62 \pm 6$ to $280 \pm 150 \mathrm{~Bq} \mathrm{~kg}^{-1}$ d.b. in the caps and from $32 \pm 9$ to $400 \pm 72 \mathrm{~Bq} \mathrm{~kg}^{-1}$ d.b. in the stipes (Table 2). No activity from ${ }^{134} \mathrm{Cs}$ was detected at the time of the measurements (summer 2015) in any of the mushroom samples investigated in this study.
The activity concentrations of ${ }^{137} \mathrm{Cs}$ in the samples of L. atrostipitatum, L. chromapes, L. extremiorientale, L. griseum, and L. rugosiceps from Yunnan region were roughly similar $\left(<4.4-12 \pm 1 \mathrm{~Bq} \mathrm{~kg}^{-1}\right.$ d.b. in the caps and $<3.2-11 \pm 2 \mathrm{~Bq} \mathrm{~kg}^{-1}$ d.b. in stipes). An exception was L. rugosiceps from Weixi in Diqing where activity concentrations of ${ }^{137} \mathrm{Cs}$ were $38 \pm 3 \mathrm{~Bq} \mathrm{~kg}{ }^{-1}$ d.b. (caps) and $19 \pm 1 \mathrm{~Bq} \mathrm{~kg}^{-1}$ d.b. (stipes) (Table 2). The highest activity concentrations of ${ }^{137} \mathrm{Cs}$ equal to $83 \pm 3 \mathrm{~Bq} \mathrm{~kg}^{-1}$ d.b. in caps and to $37 \pm 3 \mathrm{~Bq} \mathrm{~kg}^{-1}$ d.b. in stipes were found in the sample of $L$. versipelle from Pudacuo in Diqing. Both the Weixi and Pudacuo sites in Diqing region are located on the Yungui plateau in the northwest of Yunnan. A higher activity concentration of ${ }^{137} \mathrm{Cs}$ in L. rugosiceps and L. versipelle from the Diqing region could be related to the specific location of the sites rather than a possible higher capacity of $L$. versipelle for contamination, but this was not tested in this study. In a review by Duff and Ramsey (2008), no information is provided on the capacity of Leccinum spp. for contamination with ${ }^{137} \mathrm{Cs}$. A major reason for a species-specific difference in susceptibility to contamination with radiocaesium in mushrooms is related to the status of stable $\mathrm{Cs}\left({ }^{133} \mathrm{Cs}\right)$, which is better accumulated by certain species of mushrooms but less by other species under the same field conditions (Falandysz and Borovička 2013; Yoshida et al. 2000). As mentioned, specific meteorological conditions, e.g., heavy rainfall, can concentrate the radioactive fallout into localized areas (hot spots) (Smith 1994; Strzelecki et al. 1993), and if this happens in forested areas, it results in much more intense radiation accumulated in mushrooms there (Mietelski et al. 2010; Strandberg 2004).

The activity concentrations of ${ }^{137} \mathrm{Cs}$ in the samples of L. scabrum and L. variicolor from the subalpine region of Minya Konka were roughly similar $180 \pm 10$ $220 \pm 110 \mathrm{~Bq} \mathrm{~kg}^{-1} \mathrm{~d} . \mathrm{b}$. in the caps and $120 \pm 8$ $180 \pm 24 \mathrm{~Bq} \mathrm{~kg}^{-1}$ d.b. in stipes and were much higher when compared to Leccinum mushrooms from Yunnan Province in this study (Table 1). Minya Konka in the eastern Tibetan plateau is situated north of Yunnan province and northeast of Diqing region (Fig. 1). Diqing region of Yunnan is different from other regions of the province because of a colder climate and higher elevation and the climate of Minya Konka is also widely different.

The Cortinarius spp. and Russula spp. from the subalpine area of Minya Konka both showed a higher concentration activity of ${ }^{137} \mathrm{Cs}$ than mushrooms sampled in Yunnan, and Cortinarius bovinus with ${ }^{137} \mathrm{Cs}$ activity level at $280 \pm 150 \mathrm{~Bq} \mathrm{~kg}^{-1}$ d.b. in the caps and at $400 \pm 72 \mathrm{~Bq} \mathrm{~kg}^{-1}$ d.b. in the stipes was the most contaminated species. It is known that among mushrooms of the genus Cortinarius, some can much better accumulate radiocaesium in fruit bodies than others (Bakken and Olsen 1990; Zalewska et al. 2016).

Tricholoma matsutake is most famous and expensive among the gourmet mushrooms of Yunnan. One pooled 
Fig. 2 Minimum and maximum values of activity concentrations of ${ }^{137} \mathrm{Cs}$ and ${ }^{40} \mathrm{~K}$ and of assessed annual effective doses $(\mu \mathrm{Sv})$ per $1 \mathrm{~kg}$ fresh mushrooms consumed in Yunnan

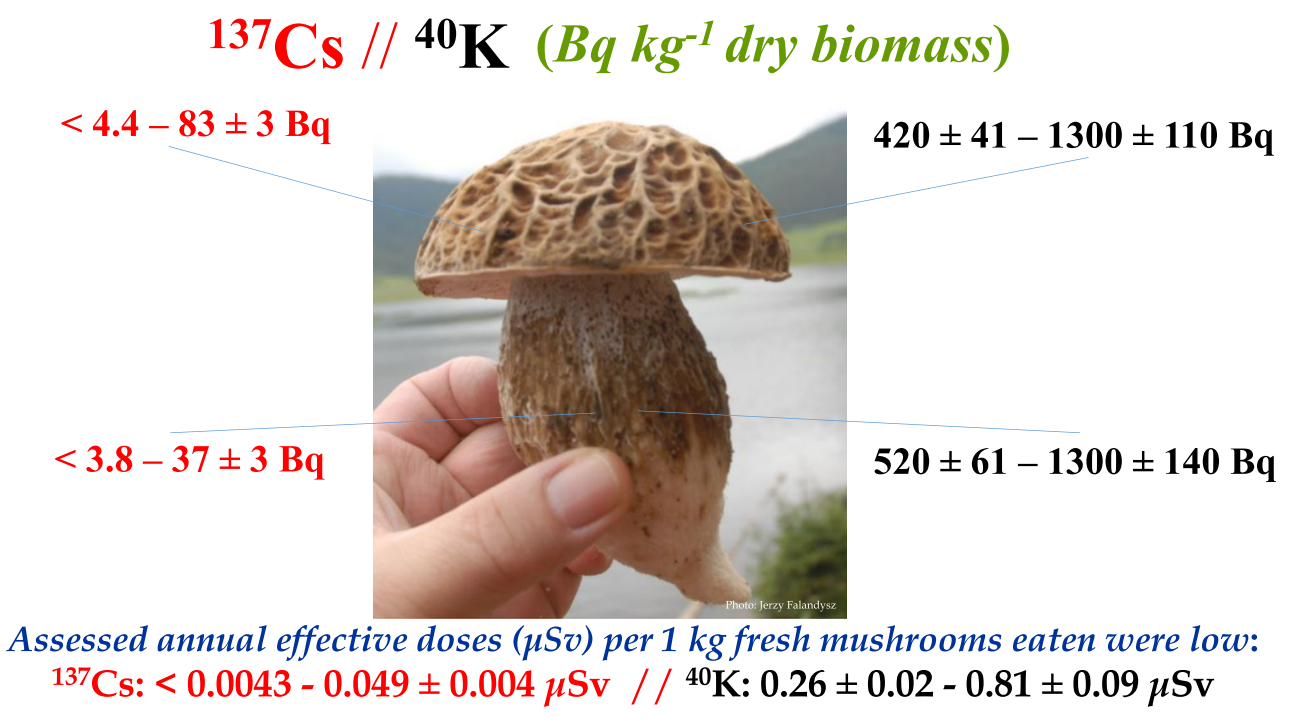

sample of ten caps of T. matsutake from the Shangri-La area (Diqing region) on the Yungui plateau collected less than 1 year before the Fukushima Dai-ichi nuclear power plant accident on March 11, 2011, showed a low concentration activity of ${ }^{137} \mathrm{Cs}$, i.e., at $14 \pm 3 \mathrm{~Bq} \mathrm{~kg}^{-1}$ d.b. ( ${ }^{134} \mathrm{Cs}$ undetected). A pooled sample of ten caps of $T$. matsutake collected from the Pudacuo area in the Diqing region 1 year after the Fukushima accident showed the same degree of contamination with ${ }^{137} \mathrm{Cs}$ ( ${ }^{134} \mathrm{Cs}$ undetected) as the pre-Fukushima sample (Table 1). Two other pooled samples of the caps of T. matsutake collected from central region of Yunnan showed ${ }^{137} \mathrm{Cs}$ in $8.5 \pm 1.6 \mathrm{~Bq} \mathrm{~kg}^{-1}$ d.b. in 2012 and in $19 \pm 2 \mathrm{~Bq} \mathrm{~kg}^{-1}$ d.b. in 2013; therefore, activity concentrations are relatively low and in accordance with data for this species from Diqing region. This result implies that the radioactive plume from the Fukushima release, which arrived via global atmospheric circulation to the northern part of the Yungui plateau, as has been documented by Wan et al. (2014), was in practice without effect in that area. This also applies to the radioactive plume in the second, regional scale event, on April 7-14, 2011, which arrived in the region of Guiyang when air masses moved at lower altitude from eastern Asia (Wan et al. 2014).

Xerocomus rubellus (former name $X$. versicolor) from the Yuxi region, which is located more or less in the center of Yunnan, did not show detectable activity from ${ }^{137} \mathrm{Cs}$ (in the caps $<3.9 \mathrm{~Bq} \mathrm{~kg}^{-1}$ d.b.). The species $B$. ferrugineus (earlier called $X$. spadiceus) showed activity concentrations of ${ }^{137} \mathrm{Cs}$ at $14 \pm 3$ to $15 \pm 1 \mathrm{~Bq} \mathrm{~kg}^{-1}$ d.b. in the caps of fruitbodies from the northwestern sites in Yunnan and at $<3.3$ to $8.2 \pm 2.1 \mathrm{~Bq} \mathrm{~kg}^{-1}$ d.b. at the more southern locations (Table 1). From the food contamination point of view, mushrooms (assumed moisture content at 90\%) both from Yunnan and Minya Konka were below the new regulatory limit of $100 \mathrm{~Bq} \mathrm{~kg}^{-1}$ fresh weight for vegetables in Japan after the Fukushima accident (effective from April 1, 2012) (Merz et al. 2015).
${ }^{137}$ Cs was usually better sequestered in caps than in stipes (index $\mathrm{Q}_{\mathrm{C} / \mathrm{S}}$ ) of fruit bodies. The median value of the index $\mathrm{Q}_{\mathrm{C} / \mathrm{S}}$ for ${ }^{137} \mathrm{Cs}$ sequestered in fruit bodies of Leccinum spp. from Yunnan was $1.3 \pm 1.2$ (range 0.5-2.2), and for Leccinum spp. from Minya Konka was in the range 1.2-1.5. The index $\mathrm{Q}_{\mathrm{C} / \mathrm{S}}$ for ${ }^{137} \mathrm{Cs}$ in Tylopilus spp. was in the range 1.0-13, in Tricholoma matsutake was 1.7-2.6 and 2.6 in Cortinarius collinitus, while $<1$ was in Cortinarius bovinus, Xerocomus spp., and Russula spp.

The activity concentrations of ${ }^{137} \mathrm{Cs}$ in mushrooms from Yunnan in this study and in limited samples of mushrooms collected in Yunnan after the Fukushima accident and examined so far were usually low, i.e., $<10 \mathrm{~Bq} \mathrm{~kg}^{-1}$ d.b. (Falandysz et al. 2015a, b, 2016a and 2017; Tuo et al. 2014; Wang et al. 2015). These results were much lower when compared to reported activity concentrations of ${ }^{137} \mathrm{Cs}$ in mushrooms foraged in eastern, central, and western Europe after the Chernobyl catastrophe - as reviewed by Duff and Ramsey (2008) and others (Falandysz and Borovička 2013; Cocchi et al. 2017; Grodzinskaya et al. 2013; Kalač 2001). Even mushrooms collected in 2004 and 2005 at a far distance from Chernobyl, e.g., from the Mediterranean, the Aegean, Marmara, the Black Sea, and from the central and eastern Anatolia regions of Turkey, usually showed ${ }^{137} \mathrm{Cs}$ at $>10 \mathrm{~Bq} \mathrm{~kg}^{-1}$ d.b., i.e., in seven species values ranged between $15 \pm 1$ and $109 \pm 6 \mathrm{~Bq} \mathrm{~kg}^{-1}$ d.b., while in four species, they were as low as between $2.4 \pm 0.3$ and $7.6 \pm 0.8 \mathrm{~Bq} \mathrm{~kg}^{-1}$ d.b. $\left({ }^{134} \mathrm{Cs}\right.$ was not detected) (Turhan et al. 2007).

Radioactive potassium $\left({ }^{40} \mathrm{~K}\right)$ is a natural and long-lived isotope of potassium $(\mathrm{K})$, which is the most abundant metallic element in fruit bodies of mushrooms. For example, $\mathrm{K}$ was efficiently bio-concentrated by mushrooms and occurred at levels ranging from 30,000 44000 to $72,000 \pm 7000 \mathrm{mg} \mathrm{kg}^{-1} \mathrm{~d} . \mathrm{b}$. (total range $24,000-$ $87,000 \mathrm{mg} \mathrm{kg}^{-1}$ d.b.) in the annual collections of fruit body caps of mycorrhizal Paxillus involutus (Batsch) Fr., and it 
Table 2 Activity concentrations of ${ }^{137} \mathrm{Cs}$ and ${ }^{40} \mathrm{~K}\left(\mathrm{~Bq} \mathrm{~kg}{ }^{-1}\right.$ dry biomass \pm a counting uncertainty) in mushrooms from the Minya Konka (Gongga Shan $\mathrm{Mt}$ ) in the Sichuan Province and across of the Yunnan Province, China

\begin{tabular}{|c|c|c|c|c|c|c|}
\hline \multirow[t]{2}{*}{ Location, species name, and year of collection } & \multirow[t]{2}{*}{ Altitude (m a.s.l.) } & \multirow[t]{2}{*}{$n$} & \multicolumn{2}{|l|}{${ }^{137} \mathrm{Cs}$} & \multicolumn{2}{|l|}{${ }^{40} \mathrm{~K}$} \\
\hline & & & Caps & Stipes & Caps & Stipes \\
\hline \multicolumn{7}{|l|}{ Sichuan Province } \\
\hline \multicolumn{7}{|l|}{ Cortinarius bovinus Fr. } \\
\hline Minya Konka, 2012 & 3480 & $(>10)$ & $280 \pm 150^{\mathrm{a}}$ & $400 \pm 72$ & WD & WD \\
\hline \multicolumn{7}{|l|}{ Cortinarius collinitus Fr. } \\
\hline Minya Konka, 2012 & 3000 & $(>10)$ & $84 \pm 20$ & $32 \pm 9$ & $2300 \pm 1000$ & $2300 \pm 630$ \\
\hline \multicolumn{7}{|l|}{ Leccinum scabrum (Bull.) Gray } \\
\hline Minya Konka, 2012 & $2900-3000$ & (12) & $180 \pm 10$ & $120 \pm 8$ & $2000 \pm 310$ & $1900 \pm 330$ \\
\hline \multicolumn{7}{|l|}{ Leccinum variicolor Watling } \\
\hline Minya Konka, 2012 & 3000 & (6) & $220 \pm 150$ & $180 \pm 24$ & $1700 \pm 440$ & $1700 \pm 830$ \\
\hline \multicolumn{7}{|l|}{ Russula grisea Fr. } \\
\hline Minya Konka, 2012 & 3600 & $(>10)$ & $98 \pm 24$ & $110 \pm 25$ & $3600 \pm 1300$ & $2700 \pm 1200$ \\
\hline \multicolumn{7}{|l|}{ Russula puellaris Fr. } \\
\hline Minya Konka, 2012 & 3000 & (11) & $62 \pm 6$ & $70 \pm 15$ & $1500 \pm 310$ & $3800 \pm 930$ \\
\hline \multicolumn{7}{|l|}{ Yunnan Province } \\
\hline \multicolumn{7}{|l|}{ Leccinum atrostipitatum Smith et Watling } \\
\hline Pudacuo, Diqing, 2012 & 3500 & (7) & $8.2 \pm 1.2$ & $10 \pm 1$ & $1100 \pm 81$ & $990 \pm 97$ \\
\hline \multicolumn{7}{|l|}{ Leccinum chromapes (Forst.) Sing } \\
\hline Fumin, Kunming, 2011 & $\sim 1800$ & $(10)$ & $6.4 \pm 1.4$ & $9.4 \pm 1.4$ & $1300 \pm 97$ & $690 \pm 78$ \\
\hline Kunming city, 2011 & 1892 & $(10)$ & $5.3 \pm 1.3$ & $11 \pm 2$ & $950 \pm 89$ & $1100 \pm 130$ \\
\hline Jiangchuan, Yuxi, 2012 & $\sim 1600$ & (7) & $8.7 \pm 1.7$ & $8.1 \pm 2.1$ & $1200 \pm 120$ & $1300 \pm 140$ \\
\hline \multicolumn{7}{|l|}{ Leccinum extremiorientale (L.Vass.) Singer } \\
\hline Nanhua, Chuxiong, 2013 & 2245 & $(10)$ & $6.8 \pm 1.1$ & $5.6 \pm 1.0$ & $1100 \pm 81$ & $720 \pm 66$ \\
\hline \multicolumn{7}{|l|}{ Leccinum griseum (Quél.) Sing } \\
\hline Kunming city, 2011 & 1892 & (7) & $16 \pm 2$ & $19 \pm 2$ & $1300 \pm 110$ & $700 \pm 87$ \\
\hline Wuding, Chuxiong, 2011 & $\sim 2300$ & $(10)$ & $8.1 \pm 1.3$ & $9.4 \pm 1.8$ & $1200 \pm 92$ & $810 \pm 110$ \\
\hline \multicolumn{7}{|l|}{ Leccinum rugosiceps (Peck) Sing } \\
\hline Huize, Qujing, 2011 & $\sim 3600$ & $(10)$ & $11 \pm 2$ & $11 \pm 2$ & $980 \pm 120$ & $690 \pm 96$ \\
\hline Fumin, Kunming, 2011 & $\sim 1800$ & $(10)$ & $17 \pm 2$ & $8.1 \pm 1.7$ & $770 \pm 110$ & $660 \pm 100$ \\
\hline Pu'er City, 2011 & $\sim 1400$ & $(10)$ & $12 \pm 1$ & $15 \pm 1$ & $1200 \pm 77$ & $780 \pm 94$ \\
\hline Yimen,Yuxi, 2011 & $\sim 1600$ & $(10)$ & $7.6 \pm 1.9$ & $9.4 \pm 2.0$ & $1200 \pm 130$ & $900 \pm 130$ \\
\hline Yimen,Yuxi, 2012 & $\sim 1600$ & (7) & $5.4 \pm 1.3$ & $4.8 \pm 1.2$ & $980 \pm 82$ & $530 \pm 77$ \\
\hline Anning, Kunming, 2012 & $\sim 1800$ & $(10)$ & $6.3 \pm 1.1$ & $5.3 \pm 1.1$ & $880 \pm 70$ & $750 \pm 70$ \\
\hline Shilin, Kunming, 2012 & $\sim 1800$ & $(8)$ & $8.7 \pm 1.4$ & $5.9 \pm 1.3$ & $1000 \pm 82$ & $700 \pm 82$ \\
\hline Shiping, Honghe, 2012 & 1745 & $(10)$ & $9.1 \pm 1.6$ & $<3.2$ & $910 \pm 100$ & $750 \pm 83$ \\
\hline Midu, Dali, 2012 & $\sim 1700$ & $(10)$ & $4.9 \pm 1.3$ & $11 \pm 1$ & $910 \pm 94$ & $460 \pm 63$ \\
\hline Weixi, Diqing, 2012 & 2540 & (7) & $38 \pm 3$ & $19 \pm 1$ & $1200 \pm 160$ & $690 \pm 70$ \\
\hline Yuanmou, Chuxiong, 2012 & 1772 & (7) & $<4.4$ & $7.1 \pm 1.5$ & $810 \pm 120$ & $780 \pm 94$ \\
\hline \multicolumn{7}{|l|}{ Leccinum versipelle (Fr.) Snell. } \\
\hline Pudacuo, Diqing, 2012 & 3500 & (7) & $83 \pm 3$ & $37 \pm 3$ & $1100 \pm 130$ & $710 \pm 120$ \\
\hline \multicolumn{7}{|l|}{ Tricholoma matsutake (S. Ito et Imai) Sing. } \\
\hline Shangri-la, Diqing, 2010 & 3400 & $(10)$ & $14 \pm 3$ & WD & $1600 \pm 180$ & WD \\
\hline Pudacuo, Diqing, 2012 & 3500 & $(10)$ & $14 \pm 3$ & WD & $960 \pm 110$ & WD \\
\hline Yanshan, Wenshan, 2012 & $\sim 1700$ & $(10)$ & $8.5 \pm 1.6$ & $5.1 \pm 1.3$ & $1400 \pm 98$ & $1200 \pm 88$ \\
\hline Jiangchuan, Yuxi, 2013 & $\sim 1600$ & $(20)$ & $19 \pm 2$ & $7.4 \pm 1.8$ & $1900 \pm 140$ & $1500 \pm 130$ \\
\hline \multicolumn{7}{|l|}{ Tylopilus felleus (Bull.:Fr.) Karst } \\
\hline Hongta region, Yuxi, 2013 & $\sim 1600$ & $(10)$ & $9.9 \pm 1.6$ & $<5.2$ & $1400 \pm 100$ & $1300 \pm 140$ \\
\hline
\end{tabular}


Table 2 (continued)

\begin{tabular}{|c|c|c|c|c|c|c|}
\hline \multirow[t]{2}{*}{ Location, species name, and year of collection } & \multirow[t]{2}{*}{ Altitude (m a.s.l.) } & \multirow[t]{2}{*}{$n$} & \multicolumn{2}{|l|}{${ }^{137} \mathrm{Cs}$} & \multicolumn{2}{|l|}{${ }^{40} \mathrm{~K}$} \\
\hline & & & Caps & Stipes & Caps & Stipes \\
\hline Zezhou, Qujing, 2013 & $\sim 2000$ & $(10)$ & $4.6 \pm 1.1$ & $<4.0$ & $1100 \pm 75$ & $1100 \pm 110$ \\
\hline \multicolumn{7}{|l|}{ Tylopinus nigerrimus (Heim) Hongo \& Endo } \\
\hline Pudacuo, Diqing, 2012 & 3500 & $(10)$ & $5.9 \pm 1.2$ & $5.5 \pm 1.4$ & $1100 \pm 82$ & $910 \pm 88$ \\
\hline \multicolumn{7}{|c|}{ Tylopilus plumbeoviolaceoides T.H. Li, B. Song \& Y.H Shen } \\
\hline Shilin, Kunming, 2012 & $\sim 1800$ & $(10)$ & $9.0 \pm 1.5$ & $8.7 \pm 1.6$ & $1000 \pm 91$ & $1300 \pm 110$ \\
\hline Zezhou, Qujing, 2013 & 1898 & $(10)$ & $8.9 \pm 1.3$ & $6.8 \pm 1.2$ & $1000 \pm 77$ & $1100 \pm 78$ \\
\hline \multicolumn{7}{|l|}{ Tylopilus roseolus (Chiu) Tai. } \\
\hline Shiping, Honghe, 2012 & 2000 & $(8)$ & $2.8 \pm 0.9$ & $<3.6$ & $940 \pm 81$ & $940 \pm 98$ \\
\hline Gejiu, Honghe, 2012 & 2000 & (9) & $12 \pm 2$ & $9.8 \pm 1.7$ & $960 \pm 130$ & $790 \pm 110$ \\
\hline \multicolumn{7}{|c|}{ Xerocomus spadiceus (Fr.) Quél; current name Boletus ferrugineus Schaeff } \\
\hline Wuding, Chuxiong, 2011 & $\sim 1800$ & $(10)$ & $<3.7$ & $<3.8$ & $1200 \pm 120$ & $1000 \pm 130$ \\
\hline Kunming city, 2011 & 1942 & $(8)$ & $<3.3$ & $<3.2$ & $1100 \pm 99$ & $930 \pm 100$ \\
\hline Pudacuo, Diqing, 2012 & 3500 & (10) & $14 \pm 3$ & WD & $960 \pm 110$ & WD \\
\hline Lanping, Nujiang, 2012 & $\sim 1200$ & (7) & $15 \pm 1$ & $20 \pm 1$ & $420 \pm 41$ & $520 \pm 61$ \\
\hline Yimen, Yuxi, 2012 & $\sim 1600$ & (9) & $8.2 \pm 2.1$ & $12 \pm 2$ & $880 \pm 130$ & $710 \pm 110$ \\
\hline Shilin, Kunming, 2012 & $\sim 1800$ & $(9)$ & $5.6 \pm 1.4$ & $3.9 \pm 1.3$ & $730 \pm 63$ & $690 \pm 63$ \\
\hline \multicolumn{7}{|c|}{ Xerocomus versicolor E.-J. Gilbert; current name Hortiboletus rubellus (Krombh.) Šutara } \\
\hline Dayingjie, Yuxi, 2012 & $\sim 1600$ & $(10)$ & $<3.9$ & WD & $810 \pm 86$ & WD \\
\hline
\end{tabular}

$W D$ without data

ranged from $26,000 \pm 4000$ to $57,000 \pm 13,000 \mathrm{mg} \mathrm{kg}^{-1}$ d.b. (total range $17,000-78,000 \mathrm{mg} \mathrm{kg}^{-1}$ d.b.) in the caps of the saprotrophic species Macrolepiota procera (Scop.) Singer $\left({ }^{40} \mathrm{~K}\right.$ contributes at $0.0119 \%$ to total $\mathrm{K}$ ) (Brzostowski et al. 2011; Gucia et al. 2012).

When compared to ${ }^{137} \mathrm{Cs}$ in this study, ${ }^{40} \mathrm{~K}$ was better accumulated in caps than stipes of the fruit bodies of Leccinum mushrooms from Yunnan, i.e., the median value of index $\mathrm{Q}_{\mathrm{C} / \mathrm{S}}$ for ${ }^{40} \mathrm{~K}$ was $1.4(1.4 \pm 0.3$; range $0.86-2.0)$ and in Xerocomus mushrooms was $1.2(1.1 \pm 0.2$; range $0.81-1.2)$. For mushrooms from Minya Konka and Russula spp. and Tylopilus spp. from Yunnan, the values of index $\mathrm{Q}_{\mathrm{C} / \mathrm{S}}$ for ${ }^{40} \mathrm{~K}$ were 1.0 , and for Tricholoma matsutake was 1.1-1.2. Those values seem typical for different species of mushrooms and did indicate on different fate of ${ }^{137} \mathrm{Cs}$ and ${ }^{40} \mathrm{~K}$ in fruit bodies of mushrooms (Falandysz and Borovička 2013; Falandysz et al. 2016a and 2017).

There are few data published on the activity concentrations of ${ }^{137} \mathrm{Cs}$ in mushrooms foraged in Yunnan and no previous data on the same in mushrooms from Minya Konka and the eastern fringe of the Tibetan plateau. In one of our previous studies, it was shown that the activity concentrations of ${ }^{137} \mathrm{Cs}$ in sclerotia of the fungus Wolfiporia extensa across Yunnan in 2012 were low, i.e., at $<1.4$ to $7.2 \pm 1.1 \mathrm{~Bq} \mathrm{~kg}^{-1}$ d.b. $\left({ }^{134} \mathrm{Cs}\right.$ undetected) (Wang et al. 2015). Also, the pantropical mushroom Macrocybe gigantea foraged recently in the wild or cultivated in Yunnan shows low radioactivity of the radiocaesium isotopes $-{ }^{134} \mathrm{Cs}$ was undetected and ${ }^{137} \mathrm{Cs}$ concentrations were in the range from $6.8 \pm 1.3$ to $<7.0 \mathrm{~Bq} \mathrm{~kg}^{-1}$ d.b. in the caps and from $<4.8$ to $7.9 \pm 1.7 \mathrm{~Bq} \mathrm{~kg}^{-1}$ d.b. in the stipes (Falandysz et al. 2015b). Contamination with ${ }^{137} \mathrm{Cs}$ of Boletus edulis form the region of Yuxi in central part of Yunnan was between $4.7 \pm 1.3$ and $10 \pm 1 \mathrm{~Bq} \mathrm{~kg}^{-1}$ d.b. in 2011-2014, and low concentration activities were also measured in Cantharellus cibarius and Cantharellus minor in 2013, e.g., they were $1.2 \pm 0.5$ and $<1.2 \mathrm{~Bq} \mathrm{~kg}^{-1}$ d.b. (Falandysz et al. 2015a, 2016a and 2017). Contamination with ${ }^{137} \mathrm{Cs}$ of 16 species (30 individuals) of forest mushrooms in the Mangshi region in southwest Yunnan in 2012-2013 was between $0.45 \pm 0.19$ and $21 \pm 1 \mathrm{~Bq} \mathrm{~kg}^{-1}$ d.b., while it was substantially higher in three individuals of Gomphus floccosus (Schv.) Sing [current name Turbinellus floccosus (Schwein.) Earle ex Giachini \& Castellano], i.e., between $150 \pm 9$ and $340 \pm 22 \mathrm{~Bq} \mathrm{~kg}^{-1}$ d.b. (Tuo et al. 2014).

Mushrooms from Yunnan collected in 2010-2014 and examined in this and other studies were evidently less contaminated with ${ }^{137} \mathrm{Cs}$ when compared to mushrooms collected from Minya Konka (Table 2) (Falandysz et al. 2015a, b, 2016a and 2017; Tuo et al. 2014; Wang et al. 2015). There are no data published on contamination with ${ }^{137} \mathrm{Cs}$ of mushrooms from Minya Konka in the pre-Chernobyl period (up to April 26, 1986), which could reflect without any doubt an 
impact from global radioactive fallout because of the nuclear detonations. Nevertheless, the effects of the Chernobyl and Fukushima accidents were considered negligible in China (Fesenko et al. 2001; Liu et al. 2013; Pang et al. 1989; Wan et al. 2014). Hence, the activity concentrations of ${ }^{137} \mathrm{Cs}$ in soils and mushrooms in Minya Konka can be a result of fallout from the aboveground nuclear detonations.

${ }^{137} \mathrm{Cs}$ from the atmospheric fallout after the aboveground nuclear detonations was found in mushrooms from background areas in Europe (also in USA), while its activity concentrations in Europe were smaller than they were after the Chernobyl accident (Bem et al. 1990; Eckl et al. 1986; Grüter 1964; Johnson and Nayfield 1970). For example, the preChernobyl mushrooms collected in Rogóźno in Poland (500 km west of Chernobyl) in 1984 and 1985 showed a contamination with ${ }^{137} \mathrm{Cs}$ from the global atmospheric fallout due to nuclear weapon detonations at levels of $40-45 \mathrm{~Bq} \mathrm{~kg}^{-1}$ d.b. in Leccinum scabrum, 100-170 $\mathrm{Bq} \mathrm{kg}^{-1}$ d.b. in Russula ochreoleuca and 46-320 Bq kg${ }^{-1}$ d.b. in three other species; however, they were much more contaminated later as a result of the Chernobyl accident (Bem et al. 1990).

Higher deposition of ${ }^{137} \mathrm{Cs}$ from fallout resulted in greater contamination of soil substrata and mushrooms. The activity concentration of ${ }^{137} \mathrm{Cs}$ in the surface $(0-10 \mathrm{~cm})$ layer of forest soil in Minya Konka was $41 \pm 1-79 \pm 2 \mathrm{~Bq} \mathrm{~kg}^{-1}$ dry matter (d.m.) in 2012 (Table 1). Hence, if considering hypothetically no deposition of ${ }^{137} \mathrm{Cs}$ (half-life of 30.05 years) from the Chernobyl fallout in Minya Konka (unlikely) or a small to moderate deposition (possible), i.e., from $<10$ up to $20 \%$ of the total load of ${ }^{137} \mathrm{Cs}$ in soil substrata after Chernobyl, mushrooms there in $\sim 1984-1985$ could be approximately contaminated with ${ }^{137} \mathrm{Cs}$ at $100 \sim 700 \mathrm{~Bq} \mathrm{~kg}^{-1}$ d.b. This scenario seems to reflect an enhanced deposition of ${ }^{137} \mathrm{Cs}$ in the Minya Konka region (also in Yunnan) from global fallout due to the Chernobyl accident and the nuclear detonations but not because of the accident in Fukushima. This may also apply to mushrooms growing in Yunnan. It is worth mentioning that $\sim 32 \%$ of the ${ }^{137} \mathrm{Cs}$ concentration activity accumulated in mushrooms of the genus Cortinarius and from 39 to $46 \%$ in Boletus edulis from the Reggio Emilia in Italy (region affected by fallout from Chernobyl) collected in 1992-1994 was from the pre-Chernobyl fallout and respectively to that $\sim 68 \%$ and $54 \%$ to $61 \%$ was from the Chernobyl fallout (Cocchi et al. 2017; Zalewska et al. 2016).

The activity concentrations of ${ }^{40} \mathrm{~K}$ were detected in each sample of mushrooms examined in this study and the caps often were richer in this element than the stipes (Table 2). The range of ${ }^{40} \mathrm{~K}$ in the pooled samples of the caps per species and location in Yunnan was between $730 \pm 63$ and $1300 \pm 110 \mathrm{~Bq} \mathrm{~kg}^{-1}$ d.b. (an exception was the value of $420 \pm 41 \mathrm{~Bq} \mathrm{~kg}^{-1}$ d.b. in the sample of $X$. spadiceus collected near Lanping in the region of Nujiang), and in stipes, the range was between $690 \pm 63$ and $1300 \pm 140 \mathrm{~Bq} \mathrm{~kg}^{-1}$ d.b. (again only $520 \pm 61 \mathrm{~Bq} \mathrm{~kg}^{-1}$ d.b. for $X$. spadiceus in Lanping). Hence, the activity concentrations of ${ }^{40} \mathrm{~K}$ exceed around 100 -fold the values of ${ }^{137} \mathrm{Cs}$ in the Leccinum and Xerocomus mushrooms from Yunnan (Table 2).

Potassium is a major bio-metal of mushrooms (at around $3 \%$ d.b. for numerous species of soil mushrooms) and natural ${ }^{40} \mathrm{~K}$ constitutes a small part of total $\mathrm{K}$ and are absorbed from a substrate and sequestered in fruiting bodies (Falandysz and Borovička 2013; Kojta and Falandysz 2016). Because of a high abundance of $\mathrm{K}$ in mushrooms can be interesting to evaluate activity concentration from artificial radionuclides accumulated in fruiting bodies against a natural ${ }^{40} \mathrm{~K}$ as well as for risk evaluation (Wang et al. 2015). Mushrooms from the region of Minya Konka showed activity concentrations of ${ }^{40} \mathrm{~K}$ in the range from $1500 \pm 310$ to $3600 \pm 1300 \mathrm{~Bq} \mathrm{~kg}^{-1}$ d.b. in caps and from $1700 \pm 830$ to $3800 \pm 930 \mathrm{~Bq} \mathrm{~kg}^{-1}$ d.b. in stipes; therefore, these values are higher than the ones determined in mushrooms from Yunnan in this study, i.e., with range from $770 \pm 110$ to $1900 \pm 140 \mathrm{~Bq} \mathrm{~kg}^{-1}$ d.b. in caps and from $520 \pm 61$ to $1500 \pm 130 \mathrm{~Bq} \mathrm{~kg}^{-1}$ d.b. in stipes (Table 2). A reason for a higher abundance of ${ }^{40} \mathrm{~K}$ (and so also stable K) in mushrooms from Minya Konka when compared to mushrooms collected across Yunnan can be simply related to an abundance of $\mathrm{K}$ in topsoil, which therefore favors the Minya Konka dark forest soil (Table 1). On the other hand, in light of data presented in Table 1, the weathered, latosols, lateritic red earths, and red and yellow earths of Yunnan can be considered as a good resource of $\mathrm{K}$ contained in the rocky geochemical background there and this potassium is not easily leachable by the process of weathering.

A species-specific accumulation of some elements is known for certain mushrooms and examples documented for mushrooms from the wild are the elements $\mathrm{Ag}, \mathrm{As}, \mathrm{Cd}, \mathrm{Fe}$, $\mathrm{Hg}, \mathrm{Rb}, \mathrm{Se}$, or V (Borovička et al. 2010; Falandysz and Borovička 2013; Falandysz and Rizal 2016; Falandysz et al. 2007; Gąsecka et al. 2017; Horyna and Řanda 1988; Krasińska and Falandysz 2015 and 2016; Lepp et al. 1987), but this accumulation can also be site specific because of particular geogenic characteristics or because of anthropogenic (emission and deposition) influences. Absorption and accumulation of certain elements $(\mathrm{K}, \mathrm{P}, \mathrm{Mg}, \mathrm{Cu}, \mathrm{Zn})$ can be more or less regulated under typical soil substrata conditions by species (Falandysz and Borovička 2013). Data on the accumulation of the stable isotope of $\mathrm{Cs}\left({ }^{133} \mathrm{Cs}\right)$ in mushrooms are few ( ̌̌anda and Kučera 2004), and they showed speciesspecific differences in content of this metallic element among the species. Mushrooms do not discriminate between stable caesium and radiocaesium - there was a high correlation for ${ }^{133} \mathrm{Cs}$ and ${ }^{137} \mathrm{Cs}$ sequestered in the flesh of fruit bodies (Tsukada et al. 1998).

Effective radiation doses To evaluate a possible risk arising from the radioactivity for the people in Yunnan eating 
Table 3 Annual effective radiation dose $(\mu \mathrm{Sv})$ for the internal exposure of ${ }^{137} \mathrm{Cs}$ and

${ }^{40} \mathrm{~K}$ in mushrooms of the genus Leccinum and Russula from the Minya Konka region in Sichuan Province and Leccinum and Xerocomus from the Yunnan Province, China

\begin{tabular}{|c|c|c|c|c|}
\hline \multirow{4}{*}{$\begin{array}{l}\text { Location, mushroom, and year of } \\
\text { collection }\end{array}$} & \multicolumn{4}{|c|}{ Annual effective radiation dose $(\mu \mathrm{Sv})^{\mathrm{c}}$} \\
\hline & \multicolumn{2}{|l|}{${ }^{137} \mathrm{Cs}$} & \multicolumn{2}{|l|}{${ }^{40} \mathrm{~K}$} \\
\hline & \multicolumn{2}{|l|}{ Fruiting bodies } & \multicolumn{2}{|c|}{ Fruiting bodies } \\
\hline & Caps & Stipes & Caps & Stipes \\
\hline \multicolumn{5}{|l|}{ Sichuan Province } \\
\hline \multicolumn{5}{|l|}{ Leccinum scabrum (Bull.) Gray } \\
\hline Minya Konka, 2012 & $0.23 \pm 0.03$ & $0.16 \pm 0.01$ & $1.3 \pm 0.2$ & $1.2 \pm 0.2$ \\
\hline \multicolumn{5}{|l|}{ Leccinum variicolor Watling } \\
\hline Minya Konka, 2012 & $0.29 \pm 0.20$ & $0.23 \pm 0.03$ & $1.1 \pm 0.3$ & $1.1 \pm 0.5$ \\
\hline \multicolumn{5}{|l|}{ Russula grisea Fr. } \\
\hline Minya Konka, 2012 & $0.13 \pm 0.03$ & $0.14 \pm 0.03$ & $2.2 \pm 0.8$ & $1.7 \pm 0.7$ \\
\hline \multicolumn{5}{|l|}{ Russula puellaris $F r$. } \\
\hline Minya Konka, 2012 & $0.081 \pm 0.008$ & $0.091 \pm 0.020$ & $0.93 \pm 0.19$ & $2.4 \pm 0.6$ \\
\hline \multicolumn{5}{|l|}{ Yunnan Province } \\
\hline \multicolumn{5}{|c|}{ Leccinum atrostipitatum Smith et Watling } \\
\hline Pudacuo, Diqing; 2012 & $0.011 \pm 0.002^{\mathrm{b}}$ & $0.013 \pm 0.001$ & $0.68 \pm 0.05$ & $0.61 \pm 0.06$ \\
\hline \multicolumn{5}{|l|}{ Leccinum chromapes (Forst.) Sing } \\
\hline Fumin, Kunming; 2011 & $0.0083 \pm 0.0018$ & $0.012 \pm 0.002$ & $0.81 \pm 0.06$ & $0.43 \pm 0.05$ \\
\hline Kunming City; 2011 & $0.0069 \pm 0.0017$ & $0.014 \pm 0.003$ & $0.59 \pm 0.05$ & $0.68 \pm 0.08$ \\
\hline Jiangchuan, Yuxi; 2012 & $0.011 \pm 0.002$ & $0.010 \pm 0.003$ & $0.74 \pm 0.07$ & $0.81 \pm 0.09$ \\
\hline \multicolumn{5}{|c|}{ Leccinum extremiorientale (L.Vass.) Singer } \\
\hline Nanhua, Chuxiong; 2013 & $0.0088 \pm 0.0014$ & $0.0073 \pm 0.0013$ & $0.68 \pm 0.05$ & $0.45 \pm 0.04$ \\
\hline \multicolumn{5}{|l|}{ Leccinum griseum (Quél.) Sing } \\
\hline Kunming City; 2011 & $0.021 \pm 0.003$ & $0.025 \pm 0.003$ & $0.81 \pm 0.07$ & $0.43 \pm 0.05$ \\
\hline Wuding, Chuxiong; 2011 & $0.010 \pm 0.002$ & $0.012 \pm 0.002$ & $0.74 \pm 0.06$ & $0.50 \pm 0.07$ \\
\hline \multicolumn{5}{|l|}{ Leccinum rugosiceps (Peck) Sing } \\
\hline Huize, Qujing; 2011 & $0.014 \pm 0.003$ & $0.014 \pm 0.003$ & $0.61 \pm 0.07$ & $0.43 \pm 0.06$ \\
\hline Fumin, Kunming; 2011 & $0.022 \pm 0.003$ & $0.010 \pm 0.002$ & $0.48 \pm 0.07$ & $0.41 \pm 0.06$ \\
\hline Pu'er City; 2011 & $0.016 \pm 0.001$ & $0.019 \pm 0.001$ & $0.74 \pm 0.05$ & $0.53 \pm 0.05$ \\
\hline Yimen,Yuxi; 2011 & $0.010 \pm 0.002$ & $0.012 \pm 0.003$ & $0.74 \pm 0.08$ & $0.56 \pm 0.08$ \\
\hline Yimen, Yuxi; 2012 & $0.0070 \pm 0.0017$ & $0.0062 \pm 0.0016$ & $0.61 \pm 0.05$ & $0.33 \pm 0.05$ \\
\hline Anning, Kunming; 2012 & $0.0082 \pm 0.0014$ & $0.0069 \pm 0.0014$ & $0.55 \pm 0.04$ & $0.46 \pm 0.04$ \\
\hline Shilin, Kunming; 2012 & $0.011 \pm 0.002$ & $0.0077 \pm 0.0017$ & $0.62 \pm 0.05$ & $0.43 \pm 0.05$ \\
\hline Shiping, Honghe; 2012 & $0.012 \pm 0.002$ & $<0.0042$ & $0.56 \pm 0.06$ & $0.46 \pm 0.05$ \\
\hline Midu, Dalil; 2012 & $0.0064 \pm 0.0017$ & $0.014 \pm 0.001$ & $0.56 \pm 0.06$ & $0.28 \pm 0.04$ \\
\hline Weixi, Diqing; 2012 & $0.049 \pm 0.004$ & $0.025 \pm 0.001$ & $0.74 \pm 0.10$ & $0.43 \pm 0.04$ \\
\hline Yuanmou, Chuxiong; 2012 & $<0.0057$ & $0.0092 \pm 0.0019$ & $0.50 \pm 0.07$ & $0.48 \pm 0.06$ \\
\hline \multicolumn{5}{|l|}{ Leccinum versipelle (Fr.) Snell. } \\
\hline Pudacuo, Diqing; 2012 & $0.11 \pm 0.00$ & $0.048 \pm 0.004$ & $0.68 \pm 0.08$ & $0.44 \pm 0.07$ \\
\hline \multicolumn{5}{|c|}{ Xerocomus spadiceus (Fr.) Quél; Boletus ferrugineus Schaeff } \\
\hline Wuding, Chuxiong; 2011 & $<0.0048$ & $<0.005$ & $0.74 \pm 0.07$ & $0.62 \pm 0.08$ \\
\hline Kunming City; 2011 & $<0.0043$ & $<0.004$ & $0.68 \pm 0.06$ & $0.58 \pm 0.06$ \\
\hline Pudacuo, Diqing; 2012 & $0.018 \pm 0.003$ & WD & $0.59 \pm 0.07$ & WD \\
\hline Lanping, Nujiang; 2012 & $0.019 \pm 0.001$ & $0.026 \pm 0.001$ & $0.26 \pm 0.02$ & $0.32 \pm 0.04$ \\
\hline Yimen, Yuxi; 2012 & $0.011 \pm 0.003$ & $0.016 \pm 0.003$ & $0.55 \pm 0.08$ & $0.44 \pm 0.07$ \\
\hline Shilin, Kunming; 2012 & $0.0073 \pm 0.0018$ & $0.0051 \pm 0.0017$ & $0.45 \pm 0.04$ & $0.43 \pm 0.04$ \\
\hline \multicolumn{5}{|c|}{ Xerocomus versicolor E.-J. Gilbert; current name Hortiboletus rubellus (Krombh.) Šutara } \\
\hline Dayingiie, Yuxi; 2012 & $<0.0051$ & WD & $0.50 \pm 0.05$ & WD \\
\hline
\end{tabular}

$W D$ without data

${ }^{\text {a }}$ Assumed that moisture content of fruiting bodies is at consensus value of $90 \%$ and the annual consumption rate of fresh mushrooms of the genus Leccinum, Russula or Xerocomus is $1000 \mathrm{~g}$ per capita

${ }^{\mathrm{b}} \pm$ Measurement uncertainty

${ }^{\mathrm{c}}$ The dose conversion factors for ${ }^{137} \mathrm{Cs}$ and ${ }^{40} \mathrm{~K}$ were $1.3 \times 10^{-8}$ and $6.2 \times 10^{-9} \mathrm{~Sv} \mathrm{~Bq}^{-1}$, respectively (Gaso et al. 2000) mushrooms, the annual effective dose from internal exposure to ${ }^{137} \mathrm{Cs}$ and ${ }^{40} \mathrm{~K}$ from mushroom meals has been assessed. The nuclide ${ }^{137} \mathrm{Cs}$ leaches out considerably from the flesh when mushrooms are blanched (parboiled) (Daillant et al.
2013; Skibniewska and Smoczyński 1999). The stable alkali elements such as $\mathrm{Cs}, \mathrm{K}$, or Rb and leach out similarly into the aqueous phase during the blanching of mushrooms, and also leach numerous other metallic elements (Drewnowska et al. 
2017a and b; Falandysz and Drewnowska 2017). The aqueous solution from blanched mushrooms is usually discarded. Hence, in practice, blanching highly reduces the annual radiation effective dose resulting from internal exposure to ${ }^{137} \mathrm{Cs}$ in consumed mushrooms. Also, frying of fresh mushrooms with vegetable oil decreases the nuclide ${ }^{137} \mathrm{Cs}$ content in cooked products because of leaching out of the ${ }^{137} \mathrm{Cs}$ (Steinhauser et al. 2014).

In Yunnan, some mushrooms, e.g., Macrocybe gigantea, are well blanched, before being used as a soup. In southwest China, the mushrooms are sometimes boiled together with vegetables and other ingredients, and the "soup" may be consumed (poured into a bowl of rice). In Yunnan, mushrooms of the genera Boletus, Leccinum, and Xerocomus and others with pores are generally cooked using a wok (Falandysz and Borovička 2013). Cooking in a wok, because of its specific cooking conditions and procedures, will probably not lead to a significant (as high as blanching) reduction of ${ }^{137} \mathrm{Cs}$ (also $\mathrm{K}$, $\mathrm{Cs}, \mathrm{Rb}, \mathrm{Li}$ ) in a mushroom meal but this was not examined in this study. No original data are known about the impact of cooking using a wok on the fate of the alkali elements contained in cooked mushrooms. Hence, when assessing the annual effective dose from internal exposure to ${ }^{137} \mathrm{Cs}$ and ${ }^{40} \mathrm{~K}$ when eating meals of Leccinum and Xerocomus by consumers in Yunnan, leaching out of both nuclides was not considered in the calculations. The wild growing edible mushrooms are a popular food item in Yunnan; hence, the annual rate of consumption was assessed as $1 \mathrm{~kg}$ per capita but regionally this could be over $20 \mathrm{~kg}$ (Zhang et al. 2010).

The assessed figures of the annual effective radiation dose for internal exposure to ${ }^{137} \mathrm{Cs}$ and ${ }^{40} \mathrm{~K}$ for mushrooms from the Yunnan and Minya Konka examined in this study were calculated using the formula (1) (ICRP 1993) and were presented in Table 3 and Fig. 2.

$E_{\mathrm{I}}=C_{\mathrm{I}} d_{\mathrm{I}}(x \times 0.1)$

where

$E_{\mathrm{I}} \quad$ the annual effective dose from isotope ingestion of different mushroom species

$C_{\mathrm{I}} \quad$ activity concentration of isotope in mushroom (Bq $\mathrm{kg}^{-1}$ d.b.)

$d_{\mathrm{I}} \quad$ isotope dose coefficient $\left(1.3 \times 10^{-8} \mathrm{~Sv} \mathrm{~Bq}^{-1}\right.$ for ${ }^{137} \mathrm{Cs} ; 6.2 \times 10^{-9} \mathrm{~Sv} \mathrm{~Bq}^{-1}$ for ${ }^{40} \mathrm{~K}$ )

$(x \times \quad$ annual mushroom consumption per capita (kg d.b.

0.1) year ${ }^{-1}$ ) based on the assumption that water content of fruitbodies is at $90 \%$

$x \quad$ annual mushroom consumption per capita (kg fresh mushrooms year ${ }^{-1}$ )

The annual effective radiation dose figures due to ${ }^{137} \mathrm{Cs}$ in mushrooms, depending on morphological part, species, and location in Yunnan, range from $<0.0043$ to $0.049 \pm 0.004 \mu \mathrm{Sv}$ and for ${ }^{40} \mathrm{~K}$ range from $0.26 \pm 0.02$ to $0.81 \pm 0.09 \mu \mathrm{Sv}$, and in Minya Konka from $0.013 \pm 0.001$ to $0.29 \pm 0.20 \mu \mathrm{Sv}$ for ${ }^{137} \mathrm{Cs}$ and from $0.93 \pm 0.19$ to $2.4 \pm 0.6 \mu \mathrm{Sv}$ for ${ }^{40} \mathrm{~K}$. If considering a maximal figure for mushroom consumption by some locals in Yunnan, the figures above have to be multiplied by 20-30. Both figures obtained for the annual effective radiation dose for ${ }^{137} \mathrm{Cs}$ and ${ }^{40} \mathrm{~K}$ contained in mushrooms in Yunnan and Minya Konka are very low. The effective dose from ${ }^{40} \mathrm{~K}$ contained in mushrooms from Yunnan and Minya Konka were an order of magnitude greater than from ${ }^{137} \mathrm{Cs}$.

\section{Conclusions}

A higher radioactive contamination of forest topsoil and mushrooms from the Alpine region of southwestern China, when compared to neighboring areas at lower elevation, e.g., Yunnan Province, can be attributed to difference in climate that is substantially colder in the subalpine area of Minya Konka, a finding which can be stimulating for further research there. Nevertheless, an overall contamination with ${ }^{137} \mathrm{Cs}$ of forest topsoil and mushrooms from the Alpine region of southwestern China and neighboring areas at lower elevation and assessed the annual effective dose from ${ }^{137} \mathrm{Cs}$ ingestion of different mushroom species there can be considered as low or very low.

Funding This study has been supported in part by the National Natural Science Foundation of China under grant no. 31660591 .

\section{Compliance with ethical standards}

Conflict of interest The authors declare that they have no conflict of interest.

Open Access This article is distributed under the terms of the Creative Commons Attribution-NonCommercial 4.0 International License (http:// creativecommons.org/licenses/by-nc/4.0/), which permits any noncommercial use, distribution, and reproduction in any medium, provided you give appropriate credit to the original author(s) and the source, provide a link to the Creative Commons license, and indicate if changes were made.

\section{References}

Bakken LR, Olsen RA (1990) Accumulation of radiocaesium in fungi. Can J Microbiol 36:704-710

Bem H, Lasota W, Kuśmierek E, Witusik M (1990) Accumulation of ${ }^{137} \mathrm{Cs}$ by mushrooms from Rogoźno area of Poland over the period 1984-1988. J Radioanal Nucl Chem Lett 145:39-46

Betti L, Palego L, Lucacchini A, Giannaccini G (2017) ${ }^{137}$ Caesium in samples of wild-grown Boletus edulis Bull. from Lucca province 
(Tuscany, Italy) and other Italian and European geographical areas. Food Addit Contam Part A 34:49-55

Brzostowski A, Jarzyńska G, Kojta AK, Wydmańska D, Falandysz J (2011) Variations in metal levels accumulated in Poison Pax (Paxillus involutus) mushroom collected at one site over four years. J Environm Sci Health Part A 46:581-588

Borovička J, Kotrba P, Gryndler M, Mihaljevič M, Řanda Z, Rohovec J, Cajthaml T, Stijve T, Dunn CE (2010) Bioaccumulation of silver in ectomycorrhizal and saprobic macrofungi from pristine and polluted areas. Sci Total Environ 408:2733-2744

Chatterjee S, Sarma MK, Deb U, Steinhauser G, Walther C, Gupta DK (2017) Mushrooms: from nutrition to mycoremediation. Environ Sci Pollut Res 24:19,480-19,493

Cocchi L, Kluza K, Zalewska T, Apanel A, Falandysz J (2017) Radioactive caesium $\left({ }^{134} \mathrm{Cs}\right.$ and $\left.{ }^{137} \mathrm{Cs}\right)$ in mushrooms of the genus Boletus from the Reggio Emilia in Italy and Pomerania in Poland. Isotopes Environ Health Stud 53:620-627. https://doi.org/10.1080/ 10256016.2017.1337761

Curie LA (1968) Limits for qualitative detection and quantitative determination. Application to radiochemistry. Anal Chem 40:586-593

Daillant O, Boilley D, Josset M, Hettwig B, Fischer HW (2013) Evolution of radiocaesium contamination in mushrooms and influence of treatment after collection. J Radioanal Nucl Chem 297:437441

DeWayne Cecil L, Naftz DL, Schuster PF, Susong DD, Green JR (1999) Glaciers of Asia - the paleoenvironmental record preserved in middle-latitude, high-mountain glaciers - an overview of the U.S. Geological Survey Experience in Central Asia and the United States. pp. F355-F349. In Satellite Image Atlas of Glaciers of the World. RS Williams Jr, JG Ferrigno (Eds) U.S. Geological Survey Professional Paper 1386-F-8

Drewnowska M, Falandysz J, Chudzińska M, Hanć A, Saba M, Barałkiewicz D (2017a) Leaching of arsenic and sixteen metallic elements from Amanita fulva mushrooms after food processing. LWT - Food Sci Technol 84:861-866

Drewnowska M, Hanć A, Barałkiewicz D, Falandysz J (2017b) Pickling of chanterelle Cantharellus cibarius mushrooms highly reduce cadmium contamination. Environ Sci Pollut Res 23:21,733-212173

Duff MC, Ramsey ML (2008) Accumulation of radiocesium by mushrooms in the current literature review. J Environ Radioact 99:912932

Eckl P, Hofmann W, Türk R (1986) Uptake of natural and man-made radionuclides by lichens and mushrooms. Radiat Environ Biophys 25:43-54

Falandysz J, Borovička J (2013) Macro and trace mineral constituents and radionuclides in mushrooms: health benefits and risks. Appl Microbiol Biotechnol 97:477-501

Falandysz J, Kunito T, Kubota R, Lipka K, Mazur A, Falandysz JJ, Tanabe S (2007) Selected elements in Fly Agaric Amanita muscaria. J Environ Sci Health Part A 42:1615-1623

Falandysz J, Dryżałowska A, Saba M, Wang J, Zhang D (2014) Mercury in the fairy-ring of Gymnopus erythropus (Pers.) and Marasmius dryophilus (Bull.) P. Karst. mushrooms from the Gongga Mountain, Eastern Tibetan Plateau. Ecotoxicol Environ Saf 104: $18-22$

Falandysz J, Zalewska T, Krasińska G, Apanel A, Wang Y, Pankavec S (2015a) Evaluation of the radioactive contamination in Fungi genus Boletus in the region of Europe and Yunnan Province in China. Appl Microbiol Biotechnol 99:8217-8224

Falandysz J, Zhang J, Zalewska T, Apanel A, Wang Y, Wiejak A (2015b) Distribution and possible dietary intake of radioactive ${ }^{137} \mathrm{Cs},{ }^{40} \mathrm{~K}$ and ${ }^{226} \mathrm{Ra}$ with the pantropical mushroom Macrocybe gigantea in SW China. J Environ Sci Health Part A 50:941-945

Falandysz J, Rizal LM (2016) Arsenic and its compounds in mushrooms: a review. J Environ Sci Health Part C 34:217-232
Falandysz J, Zalewska T, Apanel A, Drewnowska N, Kluza K (2016b) Evaluation of the activity concentrations of ${ }^{137} \mathrm{Cs}$ and ${ }^{40} \mathrm{~K}$ in some Chanterelle mushrooms from Poland and China. Environ Sci Pollut Res 23:20,039-20,048

Falandysz J, Saba M, Liu H-G, Li T, Wang J, Wiejak A, Zhang J, Wang Y-Z, Zhang D (2016a) Mercury in forest mushrooms and topsoil from the Yunnan highlands and the Subalpine region of the Minya Konka Summit in the Eastern Tibetan Plateau. Environ Sci Pollut Res 23:23,730-23,741

Falandysz J, Drewnowska M (2017) Cooking can decrease mercury contamination of a mushroom meal: Cantharellus cibarius and Amanita fulva. Environ Sci Pollut Res 24:13,352-13,357

Falandysz J, Treu R (2017) Fungi and environmental pollution. J Environ Sci Health Part B 52:147

Falandysz J, Zhang J, Zalewska T (2017) Radioactive artificial ${ }^{137}$ Cs and natural ${ }^{40} \mathrm{~K}$ activity in 21 edible mushrooms of the genus Boletus species from SW China. Environ Sci Pollut Res 24:8189-8199

Fesenko SV, Soukhova NV, Sanzharovaa NI, Avila R, Spiridonov SI, Klein D, Badot PM (2001) ${ }^{137}$ Cs availability for soil to understory transfer in different types of forest ecosystems. Sci Total Environ 269:87-103

Gaso MI, Segovia N, Morton O, Cervantes ML, Godinez L, Peña P, Acosta E (2000) ${ }^{137} \mathrm{Cs}$ and relationships with major and trace elements in edible mushrooms from Mexico. Sci Total Environ 262: 73-89

Gąsecka M, Rzymski P, Mleczek M, Siwulski M, Budzyńska S, Magdziak Z, Niedzielski P, Sobieralski K (2017) The relationship between metal composition, phenolic acid and flavonoid content in Imleria badia from non-polluted and polluted areas. J Environ Sci Health Part B 52:171-177

Grodzinskaya AA, Syrchin SA, Kuchma ND, Wasser SP (2013) Macromycetes accumulative activity in radionuclide contamination conditions of the Ukraine territory. Part 6. - P.217-260, 368-373. In: Mycobiota of Ukrainian Polesie: consequences of the Chernobyl disaster. Kiev: Naukova dumka (In Russian)

Grüter H (1964) Eine selektive Anreicherung des Spaitprodukts ${ }^{137} \mathrm{Cs}$ in Pilzen. Naturwissenschaften 7:161-162

Gucia M, Jarzyńska G, Kojta AK, Falandysz J (2012) Temporal variability in twenty chemical elements content of Parasol Mushroom (Macrolepiota procera) collected from two sites over a few years. J Environ Sci Health Part B 47:81-88

Horyna J, Řanda Z (1988) Uptake of radiocesium and alkali metals by mushrooms. J Radioanal Nucl Chem Lett 127:107-120

ICRP (1993) Age-dependent doses to members of the public from intake of radionuclides-Part 2 Ingestion dose coefficients. International Commission on Radiological Protection Publication 67. Ann. ICRP 23 (3-4) Ottawa, Ontario, Canada

Johnson W, Nayfield CL (1970) Elevated levels of cesium-137 in common mushrooms (Agaricaceae) with possible relationship to high levels of cesium-137 in Whitetail Deer, 1968-1969. Radiol Health Data Rep 11:527-531

Kalač P (2001) A review of edible mushroom radioactivity. Food Chem $75: 29-35$

Kojta AK, Falandysz J (2016) Metallic elements (Ca, Hg, Fe, K, Mg, Mn, $\mathrm{Na}, \mathrm{Zn}$ ) in the fruiting bodies of Boletus badius. Food Chem 200: 206-214

Kownacka L (2001) Natural and artificial radionuclides in the tropospheric and lower stratospheric air over Poland. Nukleonika 46:175-177

Kownacka L, Jaworowski Z (1994) Nuclear weapon and Chernobyl debris in the troposphere and lower stratosphere. Sci Total Environ 144:201-215

Krasińska G, Falandysz J (2015) Mercury in Hazel Bolete Leccinum griseum and soil substratum: distribution, bioconcentration and probable dietary exposure. J Environ Sci Health Part A 50:12591264 
Krasińska G, Falandysz J (2016) Mercury in Orange Birch Bolete Leccinum versipelle and soil substratum: bio-concentration by mushroom and probable dietary intake by consumers. Environ Sci Pollut Res 23:860-869

Kirchner G, Daillant O (1998) Accumulation of ${ }^{210} \mathrm{~Pb},{ }^{226} \mathrm{Ra}$ and radioactive cesium by fungi. Sci Total Environ 222:63-70

Lepp NW, Harrison SCS, Morrell BG (1987) A role for Amanita muscaria $\mathrm{L}$. in the circulation of cadmium and vanadium in nonpolluted woodland. Environ Geochem Health 9:61-64

Letho J, Vaaramaa K, Leskinen A $(2013){ }^{137} \mathrm{Cs},{ }^{239,240} \mathrm{Pu}$ and ${ }^{241} \mathrm{Am}$ in boreal forest soil and their transfer into wild mushrooms and berries. J Environ Radioact 116:124-132

Liu L-B, Wu S, Cao J-J, Xie F, Shi Q-L, Zhang C-Y, Tang H-B, He X-B, Zhang R, Chen L-Y, Wei G-Y, Zhang Z-H, Zhang J-M, Dang H-J (2013) Monitoring of atmospheric radionuclides from the Fukushima nuclear accident and assessing their impact on Xi'an, China. Chinese Sci Bull 58:1585-1591

Longmore ME (1982) The caesium-137 dating technique and associated applications in Australia - a review. In: Ambrose W, Duerden P (eds) Archaeometry: an Australasian perspective. Australian National Univ. Press, Canberra, pp 310-321

Luo H, Zhou T, Wu H, Zhao X, Wang Q, Gao S, Li Z (2016) Contrasting responses of planted and natural forests to drought intensity in Yunnan, China. Remote Sens 8:635. https://doi.org/10.3390/ rs 8080635

Merz S, Shozugawa K, Steinhauser G (2015) Analysis of Japanese radionuclide monitoring data of food before and after the Fukushima nuclear accident. Environ Sci Technol 49:2875-2885

Mietelski JW, Dubchak S, Błażej S, Anielska T, Turnau K (2010) ${ }^{137} \mathrm{Cs}$ and ${ }^{40} \mathrm{~K}$ in fruiting bodies of different fungal species collected in a single forest in southern Poland. J Environ Radioact 101:706-711

Pang J, Zheng G, Wang L, Liu Q, Wu R, Yan F, Hou X (1989) Environmental impact of Chernobyl accident on Xi' an area and health evaluation. Nuclear Tech 12:713-719

Prăvălie G (2014) Nuclear weapons tests and environmental consequences: a global perspective. Ambio 43:729-744

Quin N, Wang J, Yang G, Chen X, Liang H, Zhang J (2015) Spatial and temporal variations of extreme precipitation and temperature events for the southwest China in 1960-2009. Geoenviron Disasters 2:4. https://doi.org/10.1186/s40677-015-0014-9

Ramola RC, Choubey VM, Prasad G, Gusain GS, Tosheva Z, Kies A (2011) Radionuclide analysis in the soil of Kumaun Himalaya, India, using gamma ray spectrometry. Current Sci 100:906-914

Řanda Z, Kučera J (2004) Trace elements in higher fungi (mushrooms) determined by activation analysis. J Radioanal Chem 259:99-107

Ren J, Zhang W, Wan Y, Chen Y (2017) Advances in the research of Yunnan's arid climate and extreme drought. Atm Climate Sci 7:2335

Saniewski M, Zalewska T, Krasińska G, Szylke N, Wang Y, Falandysz J (2016) ${ }^{90} \mathrm{Sr}$ in King Bolete Boletus edulis and certain other mushrooms consumed in Europe and China. Sci Total Environ 543:287294

Salt CA (2007) Radionuclides in grassland, heath, mire and mountain ecosystems. In: Shaw G (ed) Radioactivity in the terrestrial environment. Elsevier, Amsterdam, pp 97-126

Shuai Z, Zhao Q, Pang R, Ouyang J, Liu P, Wang Q (2016) Impact of Japan's Fukushima nuclear accident on the radiation environment of Sichuan Province. Sichuan Environ 35:92-97

Skibniewska KA, Smoczyński S (1999) Wpływ obróbki kulinarnej na poziom radiocezu w grzybach. Roczn Panstw Zakł Hig 50:157-167

Smith FB (1994) The deposition of Chernobyl caesium-137 in heavy rain and its persistent uptake by grazing sheep. Agric. Forest Meteorol 47:163-177

Species Fungorum (2015) http://www.speciesfungorum.org/Names/ SynSpecies.asp?RecordID $=550,569$. Accessed Dec 2015
Steinhauser G, Brandl A, Johnson TE (2014) Comparison of the Chernobyl and Fukushima nuclear accidents: a review of the environmental impacts. Sci Total Environ 470-471:800-817

Steinhauser G, Steinhauser V (2016) A simple and rapid method for reducing radiocesium concentrations in wild mushrooms (Cantharellus and Boletus) in the course of cooking. J Food Prot 79:1995-1999

Strandberg M (2004) Long-term trends in the uptake of radiocesium in Rozites caperatus. Sci Total Environ 327:315-321

Strumińska-Parulska DI, Szymańska K, Krasińska K, Skwarzec B, Falandysz J (2016) Determination of ${ }^{210} \mathrm{Po}$ and ${ }^{210} \mathrm{~Pb}$ in redcapped scaber (Leccinum aurantiacum) and substratum soil: bioconcentration and related dose assessment for consumers. Environ Sci Pollut Res 23:22,606-22,613

Strzelecki R, Wolkowicz S, Szewczyk J, Lewandowski P (1993) Mapa stężeń cezu w Polsce, Radiologiczne Mapy Polski, Cz. I. Państwowy Instytut Geologiczny, Warszawa

Teramage MT, Onda Y, Patin J, Kato H, Gomi T, Nam S (2014) Vertical distribution of radiocesium in coniferous forest soil after the Fukushima nuclear power plant accident. J Environ Radioact 137: $37-45$

Tsukada H, Shibata H, Sugiyama H (1998) Transfer of radiocaesium and stable caesium from substrata to mushrooms in a pine forest in Rokkasho-mura, Aomori, Japan. J Environ Radioact 39:149-160

Tuo F, Xu C, Zhang J, Li W, Zhou Q, Zhang Q, Su X (2014) Measurement of activity concentrations for ${ }^{137} \mathrm{Cs}$ and ${ }^{40} \mathrm{~K}$ in edible wild mushrooms collected from Mangshi, Yunnan province and evaluation of dose to adult (In Chinese). Chin J Radiol Med Prot 34:621-625

Turhan Ş, Köse A, Varinlioğlu A (2007) Radioactivity levels in some wild edible mushroom species in Turkey. Isotopes Environ Health Stud 43:249-256

Vaaramaa K, Solatie D, Aro L (2009) Distribution of ${ }^{210} \mathrm{~Pb}$ and ${ }^{210} \mathrm{Po}$ concentrations in wild berries and mushrooms in boreal forest ecosystems. Sci Total Environ 408:84-91

Wan E, Zheng X, Wang S, Wan G, Wang C (2014) Atmospheric pollutants transport tracks revealed from ${ }^{131} \mathrm{I},{ }^{137} \mathrm{Cs}$, and ${ }^{134} \mathrm{Cs}$ leaked from Fukushima accident and ${ }^{7} \mathrm{Be}$ and ${ }^{210} \mathrm{~Pb}$ observed at Guiyang of China. Chin J Geochem 33:248-255

Wang Y, Zalewska T, Apanel A, Zhang J, Wiejak A, Falandysz J (2015) ${ }^{137} \mathrm{Cs},{ }^{134} \mathrm{Cs}$ and natural ${ }^{40} \mathrm{~K}$ in sclerotia of Wolfiporia extensa fungus collected across of the Yunnan land in China. J Environ Sci Health Part B 50:654-658

Wu Y, Li W, Zhou J, Cao Y (2013) Temperature and precipitation at two meteorological stations on eastern slope of Gongga Mountain, SW China in the past two decades. J Mt Sci 10:370-377

Yoshida S, Muramatsu Y (1994) Accumulation of radiocesium in basidiomycetes collected from Japanese forests. Sci Total Environ 157: 197-205

Yoshida S, Muramatsu Y, Steiner M, Belli M, Pasquale A, Rafferty B, Rühm W, Rantavaara A, Linkov I, Dvornik A, Zhuchenko T (2000) Relationship between radiocesium and stable cesium in plants and mushrooms collected from forest ecosystems with different contamination levels. Proceedings of the 10th International Congress of the International Radiation Protection Association. May, Hiroshima. P-11-244

Zalewska T, Saniewski M (2011) Bioaccumulation of gamma emitting radionuclides in red algae from the Baltic Sea under laboratory conditions. Oceanologia 53:631-650

Zalewska T, Cocchi L, Falandysz J (2016) Radiocaesium in Cortinarius spp. mushrooms in the regions of the Reggio Emilia in Italy and Pomerania in Poland. Environ Sci Pollut Res 23:23,169-23,174

Zhang D, Frankowska A, Jarzyńska G, Kojta AK, Drewnowska M, Wydmańska D, Bielawski L, Wang J, Falandysz J (2010) Metals of King Bolete (Boletus edulis) collected at the same site over two years. African J Agric Res 5:3050-3055 